\title{
ON THE MECHANICS OF SURGING GLACIERS
}

\author{
By R. M. MCMEEKING ${ }^{*}$ and R. E. JOHNSON \\ (Department of Theoretical and Applied Mechanics, University of Illinois at Urbana-Champaign, Urbana,
}

Illinois 61801, U.S.A.)

\begin{abstract}
Observations of surging glaciers indicate that the flow regime is one dominated by extensional flow. The stress state has substantial longitudinal deviatoric stress. This regime is very different from the conventional model for glacier dynamics which is dominated by shearing flow. In addition, the initiation of surging of ten involves a compression front which travels down the glacier. The compression front seems to divide an up-stream region of high drag at the base of the glacier from one of low drag which allows the rapid sliding. We develop a framework for the mechanics of glaciers undergoing surging. Relevant issues are the extensional and compressional flows, high longitudinal deviatoric stress, and the stress state near the basal discontinuity. We find that some of the down-slope component of glacier weight is borne by longitudinal stress in the rapidly sliding region. This stress thrusts against the slowly moving parts of the glacier. We hypothesize that this effect causes the rapidly sliding part to spread and causes the compression front to travel down the glacier. A criterion for spreading of the rapidly sliding part is developed. The mechanics outlined above are used to develop a highly idealized model for glacier surging. We propose that regions of low drag are relatively common features of glaciers. The surge initiates when conditions are met which allow the surge nucleus to spread. The rapidly sliding region of low drag spreads to a large part of the glacier. Surging ends when the low-drag conditions terminate. Because of the changed state of the glacier, surge nuclei are now stable against spreading. Several years of rebuilding must occur before nuclei are once more unstable. Calculations are performed for the evolution of the shape of Medvezhy Glacier during the surge of 1963. We find a remarkable similarity between the data and our computations.
\end{abstract}

RÉsumé. Sur le mécanisme des avances catastrophiques. L'observation des avances catastrophiques de glacier (surge) montre que l'écoulement est essentiellement extensif, les contraintes déviatrices longitudinales étant importantes. Il s'agit d'un régime très différent de celui du modèle conventionnel de glacier, dominé par le cisaillement. En outre le déclenchement du surge entraine souvent un front de compression qui descend le glacier. Le front de compression semble séparer la partie amont du glacier où le frottement est important, de la partie aval où une faible valeur du frottement permet un glissement rapide. On développe le cadre de la mécanique des surges. Les points principaux sont les écoulements intensifs et compressifs les fortes contraintes déviatrices longitudinales et l'état de contrainte près de la discontinuité basale. Nous trouvons qu'une part de la composante du poids vers l'aval vient de la contrainte longitudinale dans les régions de glissement rapide. Cette contrainte s'exerce contre les parties à faible mouvement du glacier. Nous faisons l'hypothèse que cet effet cause une progression de la partie glissement rapidement et est à l'origine d'un front de compression qui

*Present address: Materials Program, University of California, Santa Barbara, California 93106, U.S.A. descend le glacier. Un critère de progression de glissement rapide est développé. Les mécanismes décrits ci-dessus sont utilisés pour développer un modèle très idéalisé de glacier à surge. Nous proposons que des régions a faible frottement sont des caractéristiques habituelles de glaciers. Les surges débutent quand sont réunies des conditions qui permettent au noyau de surge de s'exercer. La région de glissement rapide à faible frottement s'étend à une bonne part du glacier. La surge se termine quand les conditions de faible frottement disparaissent. Par suite de l'état modifié du glacier, les noyaux de surge sont alors stables par rapport à leur développement. Plusieurs années de reconstitution sont nécessaires avant que les noyaux soient une fois de plus instables. Des calculs sont effectués pour l'évolution de la forme du Medvezhy Glacier au cours de sa surge de 1963. Nous obtenons une remarquable similitude entre les données et nos calculs.

ZUSAMMENFASSUNG. Über den Mechanismus ausbrechender Gletscher. Beobachtungen an ausbrechenden Gletschern lassen erkennen, dass ihr Fliesszustand von extensionalem Fluss bestimmt wird. Der Spannungszustand ist durch wesentlichen ablenkenden Druck in Längsrichtung gekennzeichnet. Dieser Zustand ist sehr verschieden vom gewöhnlichen Modell der Gletscherdynamik, das vom Scherfluss beherrscht wird. Ausserdem tritt mit dem Beginn eines Ausbruchs of t eine Kompressionsfront auf, die gletscherabwărts wandert. Diese Front scheint ein stromaufwärts gelegenes Gebiet mit hoher Hemmung am Gletscherbett von einem solchen mit geringer Hemmung zu trennen, das die schnelle Gleitbewegung zulässt. Es wird ein Rahmen für die Mechanik ausbrechender Gletscher entwickelt. Massgebliche Momente sind der extensionale und kompressive Fluss, hohe ablenkende Spannung in der Lăngsrichtung und der Spannungszustand nahe der Diskontinuităt am Untergrund. Es ergibt sich, dass ein Teil der hangabwărts gerichteten Komponente des Gletschergewichts vom Lăngsdruck im schnell gleitenden Gebiet aufgenommen wird. Dieser Druck wirkt gegen die langsam bewegten Teile des Gletschers. Es wird angenommen, dass hierdurch der schnell gleitende Teil zur Ausbreitung und die Kompressionsfront zur Wanderung gletscherabwărts veranlasst wird. Für die Ausbreitung des schnell gleitenden Teils wird ein Kriterium entwickelt. Die beschriebene Mechanik wird zur Entwicklung eines stark idealisierten Modells für Gletscherausbrūche herangezogen. Man kann annehmen, dass Gebiete mit geringer Hemmung relativ hăufig am Gletscher auftreten. Der Ausbruch beginnt, wenn Verhăltnisse eintreten, die eine Ausbreitung des Ausbruchskerns erlauben. Das Gebiet schnellen Gleitens bei geringer Hemmung erfasst einen Grossteil des Gletschers. Der Ausbruch endet, wenn die Bedingungen für geringe Hemmung nicht mehr gegeben sind. Infolge des verănderten Gletscherzustandes sind die Ausbruchskerne dann unemfindlich gegen Ausbreitung. Mehrere Jahre des Wiederaufbaus sind nőtig, bevor die Kerne wieder instabil werden kőnnen. Für die Entwicklung der Gestalt des Medvezhy Glacier wăhrend seines Ausbruchs von 1963 wurden Berechnungen angestellt. Es zeigt sich eine bemerkenswerte Ähnlichkeit zwischen den Beobachtungsdaten und unseren Berechnungen. 


\section{INTRODUCTION}

A glacier surge is a relatively rapid non-seasonal extension of a glacier down its valley. Not all glaciers surge, but those which do can remain in a quiescent phase for many years with only seasonal fluctuations. Then, the motion of the ice mass accelerates over a few years in addition to there being the usual annual changes. Finally, in the year of a surge, there is a rapid stretching of the glacier which can cause the snout to move severa kilometers down the valley. Some discussion of surging glaciers can be found in Raymond (1980) and Paterson (1981). A description of the 1983 surge of Variegated Glacier has been given by Kamb and others (1985). In that case it was observed that the surging motion commenced in January 1982 in the upper part of the glacier. Preceded by a compression front, this segment extended down the ice mass and in spring 1983 the lower part was moving rapidly. By July 1983, this motion had subsided and the newly extended glacier seems to have returned to its quiescent state. Data for this and a previous surge of Variegated Glacier, and for other surging glaciers, are listed in Table I, which was adapted from a similar table in Raymond (1980). Only in two cases was the maximum velocity measured on a daily basis and an annual rate is given for the others.

Many models for glacier surge have been proposed and a summary can be found in Raymond (1980). Further proposals can be found in papers by Kamb and others (1985), based on observations of Variegated Glacier, and Clarke and others (1984) for Trapridge Glacier. A full description of the mechanics of ice motion is often lacking in these models. In this paper we attempt to establish a reliable foundation for the understanding of the mechanics of glacier surging. In addition, we analyze an idealized surge model which contains features present in the 1983 surge of Variegated Glacier (Kamb and others, 1985), the 1982 surge of Trapridge Glacier (Clarke and others, 1984), and the 1963 surge of Medvezhy Glacier (Dolgushin and Osipova, 1975).

\section{Flow regime}

Our attempt to create a foundation for the mechanics of glacier surging is based on an assessment of the glacier flow regime which develops during a surge. As discussed by Kamb and others (1985), and others (summarized by Raymond (1980)), surging involves substantial longitudinal compression and extension of the ice in the glacier. We have deduced from the published data that the longitudinal deviatoric stresses involved in this compression and extension of the ice are comparable to or substantially greater than the conventional estimate for the basal shear stress in the same glacier. McMeeking and Johnson (1985) have analyzed in some detail two-dimensional glacier mechanics when such conditions prevail and, independently, Shoemaker and Morland (1984) have modeled one particular flow regime where longitudinal deviatoric stresses are significant. These two papers show that the conventional treatment of glacier mechanics (see, for example, Hutter, [ $\left.{ }^{\mathrm{c}} 1983\right]$ ) is inappropriate for the flow regime that develops during surging. This is so because the conventional analysis is only valid where the longitudinal deviatoric stress is very small compared to the basal shear stress. This shows that a model for the stresses and flow regime during surging must be chosen with some care so that a proper foundation for the mechanics of surging can be utilized.

As a justification for the comments in the previous paragraph, we consider now the flow regime of some glaciers during surging. In Table I, we have calculated a strain-rate for each case of surging except for Variegated Glacier (1983). This calculation was done by taking the maximum velocity of the snout and dividing it by the length of the surging part of the glacier. This must be a lower bound to the maximum strain-rates that actually arise because the maximum velocity of the snout may occur due to stretching of a smaller length than the whole surging segment. In the case of Variegated Glacier (1983), Kamb and others (1985) have measured a local compressive strainrate which we have quoted in Table I. Next, we have estimated the longitudinal stress required to produce the surging strain-rates by referring to data presented by Frost and Ashby (1983). The estimates for stress taken to be twice the deviatoric stress $s_{x x}$ should be valid near the upper surface where neither shear stress nor normal pressure will be very significant. Finally, we have calculated an estimate for the basal shear stress under the usual assumption that the down-slope component of weight is

\section{TABLE I. SOME SURGING GLACIERS}

(From Raymond, 1980; Paterson, 1981)

\begin{tabular}{|c|c|c|c|c|c|c|c|}
\hline Glacier & Length & $\begin{array}{l}\text { Surge } \\
\text { length } \\
\mathrm{km}\end{array}$ & $\begin{array}{l}\text { Average } \\
\text { slope } \\
\alpha^{\circ}\end{array}$ & $\begin{array}{l}\text { Maximum veloc- } \\
\text { ity in surge } \\
\mathrm{km} / \text { year }\end{array}$ & $\begin{array}{l}\text { Longitudinal } \\
\text { strain-rate } \\
\qquad \mathrm{s}^{-1}\end{array}$ & $\begin{array}{l}\text { Required } \\
\text { stress* } \\
\left(2 s_{x x}\right) \\
\mathrm{MN} / \mathrm{m}^{2}\end{array}$ & $\begin{array}{l}\text { Basal shęar } \\
\text { stress } \\
(\rho g h \sin \alpha) \\
\mathrm{MN} / \mathrm{m}^{2}\end{array}$ \\
\hline Klutlan & 55 & 40 & 1.3 & $>3.2$ & $0.25 \times 10^{-8}$ & 0.2 & 0.04 \\
\hline Walsh & 89 & 86 & 1 & $>5.6$ & $0.21 \times 10^{-8}$ & 0.2 & 0.03 \\
\hline Muldrow & 49 & 46 & 2.2 & 6.6 & $0.45 \times 10^{-8}$ & 0.2 & 0.07 \\
\hline $\begin{array}{c}\text { Variegated } \\
(1964)\end{array}$ & 20 & 19 & 4.2 & $>5$ & $0.83 \times 10^{-8}$ & 0.2 & 0.13 \\
\hline Tyeen & 7 & 7 & 13.6 & $>1.5$ & $0.68 \times 10^{-8}$ & 0.2 & 0.42 \\
\hline Medvezhy & 13 & 6 & 5 & $105 \mathrm{~m} / \mathrm{d}$ & $2.0 \times 10^{-7}$ & 0.7 & 0.15 \\
\hline $\begin{array}{c}\text { Variegated } \ddagger \\
(1983)\end{array}$ & $\neq 20$ & 19 & 4.2 & $50 \mathrm{~m} / \mathrm{d}$ & $-2.3 \times 10^{-5}$ & -3.0 & 0.13 \\
\hline \multicolumn{8}{|c|}{$\begin{array}{l}\text { Required stress is } \sigma_{x x}-\sigma_{y y} \text { to cause longitudinal strain-rate. } \\
\bar{B}=1.5 \times 10^{-6}\left(\mathrm{~m}^{2} / \mathrm{MN}\right)^{3} \mathrm{~s}^{-1}=1.5 \times 10^{-15}(\mathrm{kPa})^{-3} \mathrm{~s}^{-1} \text {. }\end{array}$} \\
\hline
\end{tabular}


supported by shear stress at the base. For this, we have used the average slope given by Raymond (1980) and a depth of $200 \mathrm{~m}$. The key point here, which can be seen in Table $I$, is that the longitudinal stress is usually somewhat larger than the conventional estimate for basal shear stress. In one case, (Variegated Glacier, 1983), the longitudinal stress locally is an order of magnitude greater than the shear stress. As a result, we must consider the analysis of glacier mechanics for situations where longitudinal stress is comparable to or larger than the basal shear stress if we are to understand glacial surging. As noted, the analysis of this situation has been discussed in separate papers by McMeeking and Johnson (1985), and Shoemaker and Morland (1984).

The role of longitudinal stress during surging has been recognized by others such as Budd (1975). Starting with an equation which relates longitudinal stress gradients to the basal shear stress and the glacier weight, he postulated a dynamical model for surging due to variations in the basal shear stress. The model involves global averages of the basal shear stress and the physics is not entirely clear, although surges are generated. In addition, Lliboutry (1968) and others have discussed surging due to sliding laws like (a) in Figure 1 and longitudinal stress plays a part, but the details of a mathematical model are not brought out.

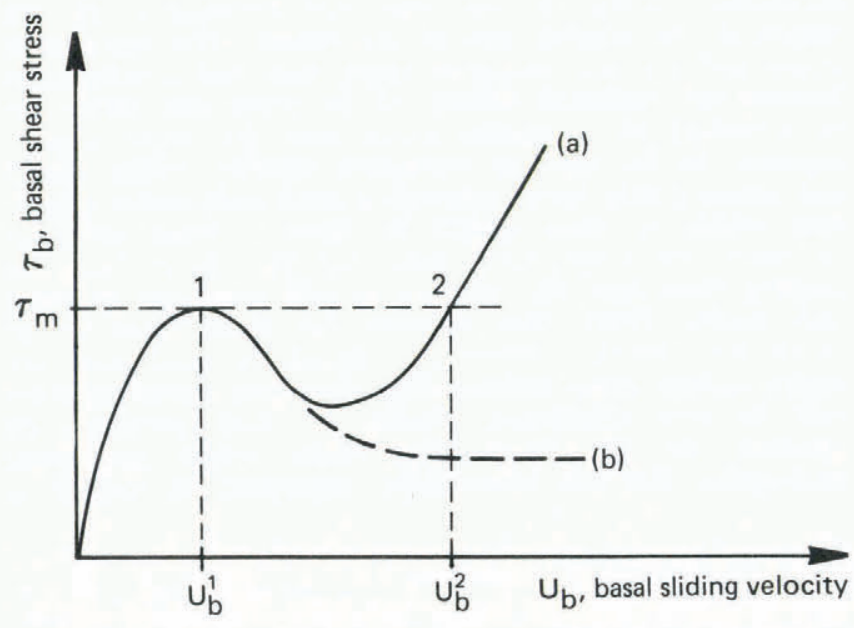

Fig. 1. Sliding law - relationship between basal shear stress and basal velocity.

\section{Compression front}

Another feature which has been observed in some glacier surges is that a compression front moves down the glacier. This was observed by Kamb and others (1985) for the 1983 Variegated Glacier surge and by Dolgushin and Osipova (1975) for Medvezhy Glacier in 1963, in the form of a bulge. Kamb and others stated that below the front in Variegated Glacier the ice was almost stagnant and above it the flow was rapid. There were very high compressive strain-rates just behind the bulge and a corresponding thickening of the glacier. In the rapidly moving segment of the ice, $95 \%$ of the surface velocity was due to sliding and the remaining $5 \%$ was due to shear flow. Kamb and others attributed the rapid sliding to highly lubricated conditions at the base. They measured basal bore-hole water levels there which fluctuated around the ice-overburden value and concluded that the ice is supported mainly by a hydraulic system. They deduced that this gives rise to a very low level of drag at the base of the glacier.

The propagating compression front seems to be a discontinuity in the sliding conditions at the base of the glacier. Ahead of the front, the base of the ice is either stuck or sliding very slowly over the foundation. Behind the front, the base of the ice is relatively free of shear drag and moving rapidly compared to the ice beyond the front. The difference in velocities gives rise to a compressive region adjacent to the slowly moving ice.
We are not in a position to say why there should be nearly stuck portions and more freely sliding portions of the glacier. Kamb and others (1985) proposed that, as the surge front propagates down Variegated Glacier, the basal hydraulic system is disrupted and alters from one which causes high drag at the base to one which causes low drag. They thought that the surge front causes the closure of drainage tunnels and that this would flood the base of the glacier. Kamb and others suggested that the tunnel closure would be due to the surging mass up-stream from the front.

If the mechanism suggested by Kamb and others (1985) for Variegated Glacier is correct, we would view its operation as follows. The surge front separates the high-drag region from a low-drag region. In the low-drag region the down-slope component of weight of the overlying ice exceeds the drag on the sole. As a consequence, some of the down-slope weight is supported by the longitudinal stress. This is the only way that the large compression and extension rates can be developed. The stress thrusts upon the region of the glacier subject to high drag and as a result some of the weight of the surging mass is being supported by the slowly moving segment of the glacier. This force is transmitted to the base as a shear stress within about one glacier thickness from the basal discontinuity. The shear stress at the base in this transition region will be much larger than elsewhere, giving rise to a shear-stress concentration.

This stress concentration will cause viscous flow of the ice to be more rapid there than elsewhere. We suggest that the enhanced stresses at the discontinuity will allow the tunnel closure in a rapid fashion as suggested by $\mathrm{Kamb}$ and others (1985). Certainly, the high stresses will perturb the equilibrium of the basal water tunnel system. The non-linear interaction in the creep response between the enhanced shearing flow and the stresses generated by the overburden pressure around the tunnels would seem to suggest the tunnels would tend to shrink by creep. They may close entirely but, in any case, some water would be squeezed out.

The ice dynamics of a model for this kind of transition at the surge front would determine the rate at which the tunnels close. This, in turn, would determine the rate at which the surge front would propagate down the glacier. However, we believe that the processes involved in the transition would be controled by the stress field developed around the shear-stress discontinuity at the base. Thus the events can be characterized by the stress concentration at the discontinuity. That, in turn, can be determined neglecting the details of tunnel closure or any other relatively small-scale process involved in the transition. As a consequence, we concern ourselves only with the gross details of the stress field near the discontinuity with the understanding that these gross features of the stress field would control the fine details in a small region near the actual discontinuity. The fine details would in turn determine the propagation rate.

\section{Basal condition discontinuity}

With the above understanding, we are in a position to consider the mechanics of a basal shear discontinuity whatever the reason for its existence. For example, the discussion above refers to Variegated Glacier which is a temperate glacier. Clark and others (1984) have discovered that there is a discontinuity at the base of Trapridge Glacier. This discontinuity is stationary and marks a transition from ice which is at the melting temperature in the upper part of the glacier and ice further down the ice stream which is frozen to the underlying stratum. It would appear that the frozen segment does not allow any basal sliding while the glacier is quiescent. However, the temperate segment slides and as a result a bulge builds up against the frozen dam. A possible surge mechanism is the failure of the frozen base due to the stress concentration or singularity at the discontinuity. This would occur probably when the stress reaches a critical level. Once the frozen base is ruptured near the discontinuity, part of the weight of the sliding ice would be thrust on to the next segment of frozen base. This, in turn, is likely to rupture and as a result a surge front would propagate down the glacier. 
Sliding more freely, the glacier would extend. As before, the stresses around the discontinuity would control the detailed rupture process. For the purposes of modeling, we can consider the overall stresses and characterize failure in terms of some critical stress level.

The picture is complicated in the case of Trapridge Glacier, because it is known to rest on deformable debris (Clarke and others, 1984). The sliding part of the glacier may be moving relative to the debris or the deformation of the debris may be causing the motion. Presumably, the segment which is stuck overlies debris which is frozen. The frozen segment of the base would fail either by the glacier shearing away from the debris or by the frozen debris failing or breaking away from unfrozen debris underneath. The propagation of the slip surface accompanying the failure in each possibility would still be controled, we think, by the stress singularity or concentration at the now propagating stuck-sliding discontinuity. The modeling of this case of a temperate-sub-polar interface as in Trapridge Glacier can be taken care of by the same overall model as would be relevant to the purely temperate case of Variegated Glacier. We will discuss only an isothermal glacier model with the understanding that the sliding discontinuity at the base incorporated into our model may actually be a feature of non-isothermal conditions as in Trapridge Glacier. The model is meant to describe the general surge features of both an isothermal and a nonisothermal glacier, although certain detailed phenomena which distinguish these two cases are omitted. In particular, the treatment of ice rheology will be deficient as to the effects of temperature variations in the glacier, but we do not believe that plays a major role in controlling surging.

\section{Hydrology}

Basal hydrology is a significant feature of glacier behavior and in some cases of surging such as Variegated Glacier (Kamb and others, 1985). We will not treat the hydrology in our model, but it should be understood that water may be at the root of features that we describe in a phenomenological way. Thus the transition from nearly stuck to low-drag conditions at the base may be due to differences in the way that water invades the sole of the ice. One example of this would be the model of Kamb and others (1985) for the closure of drainage tunnels and the redistribution of water at the base into disconnected cavities. We will not attempt to characterize the drag at the base by modeling such features as described by Kamb and others. Instead, we will use sliding laws with features that would seem to have the right character for a variety of possible phenomena, including those driven by hydrological effects. Similarly, we are unable to characterize features of a purely hydrological nature but which may play essential parts in the surge cycle. For example, if the stuck-sliding discontinuity is acting as a dam to basal water or as a severe constriction as envisaged by Kamb and others (1985), then the restrained water would be released when the discontinuity nears the snout. As it is likely that this sort of phenomenon is responsible for the termination of surging in some cases, it is clearly important. However, we can only model this behavior in our approach by asserting that surging ceases at some point. Furthermore, the conditions for termination of a surge may be due to any one of a number of reasons such as that given above. One possibility is that the supply of melt water dries up seasonally and lubrication is lost. Another is that the glacier stretches and thins to such an extent that the driving force for the fast sliding falls below the critical level for sustenance and a return to slow sliding or nearly stuck conditions occurs. Due to our neglect of such issues, our surging model is quite incomplete but nevertheless brings out several salient features of the mechanics.

\section{Basal sliding law}

Hydrological, thermal, and basal deformation effects such as those mentioned above will be modeled in a sliding law chosen to display characteristics of many of the phenomena discussed above. These laws have shapes shown in Figure 1 where the shear drag on the base is plotted against the basal sliding velocity. Lliboutry (1968) suggested that surging arose as a result of double-valued relationships between sliding velocity and drag of the kind marked (a) in Figure 1. Lliboutry based his law on an analysis of sliding with cavitation.

In addition to the above possibility, we propose that the suggestion by Kamb and others (1985) that there is a disruption of the basal drainage system near the surge front would lead to a sliding law like that marked (b) in Figure 1. Our thoughts are that the large stresses associated with sliding at velocity $u_{\mathrm{b}}^{1}$ are sufficient to close drainage tunnels and this leads to a drop in the drag and a corresponding increase in the sliding velocity. As long as the new drainage system is stable, the low-drag conditions will prevail. As mentioned previously, loss of basal water would lead to a return to high-drag conditions.

Another possibility, perhaps relevant to a partially frozen base, is that the maximum marked 1 in Figure 1 is the stress at which the base fails. Perhaps this would occur without any prior sliding (i.e. $u_{\mathrm{b}}^{1}=0$ ) and thereafter the failed base is capable of sustaining relatively low stresses while slip endures. The failure involved may occur in the ice, at the ice-base interface, or actually in the base in the case where the underlying stratum is deformable debris. To justify our assertion that a base of deformable debris may fail with the characteristics of curve (b) in Figure 1, we note the work of Roscoe (1970) on the failure of dense sand and similar granular materials such as glacial till.

We feel that sliding laws of the type shown in Figure 1 can be justified for a number of possible phenomena, although we have not attempted to characterize fully any particular case. Of course, the relevant behavior must be identified from field work before any particular case can be invoked. However, we have attempted to show that several possibilities fall within the purview of the sliding laws shown in Figure 1. There may be effects neglected in the sliding behavior and not present in the laws we consider, but we believe that the idealizations we have made retain the nature of the behavior relevant to several known surging glaciers. The absence of explicit thermal or hydrological effects from the models for surging is an idealization and a simplification helpful for the analysis. However, we will proceed with the understanding that the parameters of our sliding law may vary due to thermal or hydrological effects.

If we have omitted anything essential in the sliding law, then our surging model is invalid. It is more likely that we have simply omitted non-surging fluctuations which occur on a regular predictable basis, perhaps seasonal. Then all that occurs due to the fluctuations is that the critical condition to be met happens at one time of the year or cycle but cannot be met at other times of the year or cycle.

The overall concept is that slowly moving segments of the glacier are those sliding with a velocity up to $u_{\mathrm{b}}^{1}$ (Fig. 1). This slow motion can occur up to drag levels which are high and approach $\tau_{\mathrm{m}}$. Rapidly sliding parts of the glacier are those moving faster at the base than $u_{\mathrm{b}}^{1}$. The drag involved would fall below $\tau_{\mathrm{m}}$ at least for speeds greater than $u_{\mathrm{b}}^{1}$ by only a limited amount. Our study of the mechanics involved in glacier surging has led us to believe that the initiation of surging is bound up with the transition from speeds below $u_{b}^{1}$ to those greater than $u_{b}^{1}$. In passing, we note that we believe that phenomena bound up with sliding laws of the type shown in Figure 1 are essential for surging. If the sliding law is monotonic and never becomes otherwise but experiences seasonal fluctuations, then the motion of the glacier will be unsteady. As discussed by Fowler (1982), kinematic waves will be generated on the glacier, but it seems unlikely that any unstable surging behavior can result.

We have outlined how the down-slope component of the weight of the rapidly sliding region would thrust on to the more slowly moving segment, raising the basal shear stresses there. We envisage that these high stresses cause the mechanisms of transition to operate and so the rapidly sliding region would extend into previously slowly moving segments of the glacier. The peak drag $\tau_{\mathrm{m}}$ (see Fig. 1) would determine the thrust required for transition
mechanisms to operate and so that would specify the conditions under which the sliding region would spread. Of 


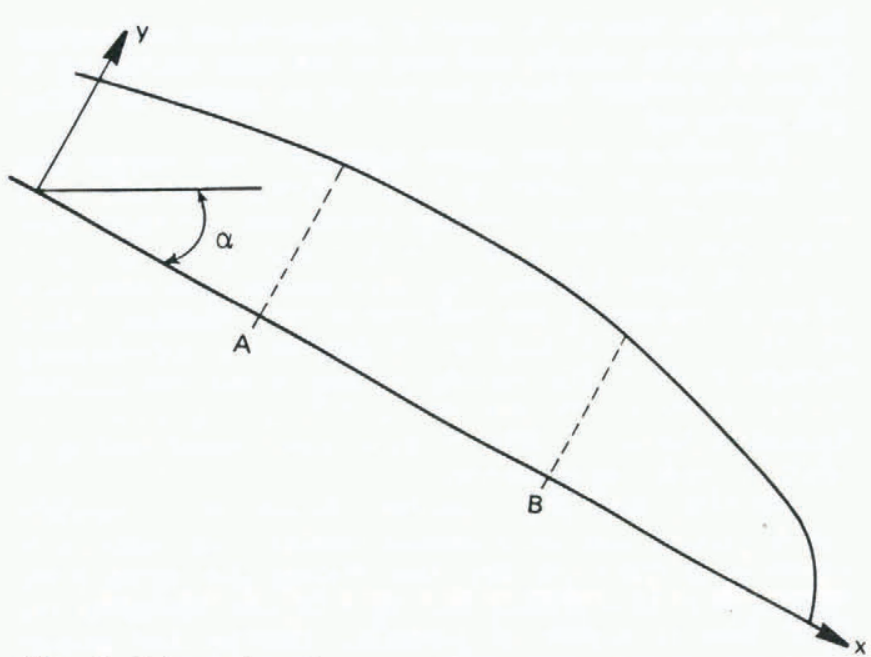

Fig. 2. Schematic of a non-sliding glacier with a rapidly sliding segment $\mathbf{A B}$.

course, this parameter would vary from point to point in the glacier. In addition, we would expect that there would be seasonal fluctuations due to melt-water flow or other effects.

Consider there to be a segment $\mathbf{A B}$ of the glacier in Figure 2. In this segment, the local peak drag $\tau_{\mathrm{m}}$ would be exceeded by the down-slope component of the weight of the ice overhead. As a result, the down-slope component of the weight of AB would no longer be borne completely by the basal shear stress and the excess would have to be taken up by the longitudinal stress. Simultaneously, the segment would commence rapid sliding (the governing equations require large velocities when the longitudinal stress is significant; (see McMeeking and Johnson (1985)). In turn, the longitudinal stress would thrust on to neighboring parts of the glacier outside $A B$ and would tend to increase the shear stress at the base there. If the resulting basal shear stress is below the local $\tau_{m}$, then the segment $\mathbf{A B}$ would be stable. If the shear stress at the base of the neighboring segments tends to exceed the local $\tau_{m}$, then the region of rapid sliding would spread. This would involve a traveling compression front as discussed by Kamb and others (1985) and Paterson (1981), or a traveling tensile front. As the sliding region spreads, increased weight would be thrust on to the slowly sliding parts, and so spreading would tend to continue.

The phenomenon of spreading would occur whether a law like (a) or (b) in Figure 1 were involved. In case (a) at a later stage, some of the rapidly sliding ice could be doing so with the down-slope weight borne by shear stresses at the base, that is, to the right of point 2 in Figure 1. This corresponds to what is called "continuously fast" sliding (Raymond, 1980). On the other hand, if the law is like (b), some down-slope weight would always be supported by longitudinal stresses in the rapidly sliding region.

\section{Idealization of the sliding law}

Since we believe that the processes in a developing surge are bound up with behavior near the peak drag in laws like those shown in Figure 1, we will concern ourselves with modeling the sliding law around point 1 in Figure 1. At sliding speeds less than $u_{b}^{1}$, the down-slope component of the weight of the glacier is supported by the basal drag and the basal sliding speeds are relatively low. A substantial part of the ice flux is due to shearing flow. We will model this situation as one in which there is a no-slip condition at the base of the glacier. This modeling is possible because the no-slip condition gives rise to an ice flux solely due to shearing flow and a leading order basal shear stress which supports all of the down-slope component of glacier weight.

At sliding speeds greater than $u_{b}^{1}$ in Figure 1 , the down-slope component of glacier weight will generally exceed the basal drag and most of the ice flux will be due to the basal velocity with very little due to shearing. We will model this situation as one of constant drag $\tau_{s}$ at any sliding speed. This will give rise to an ice flux dominated by the basal velocity and some of the down-slope component of weight will be shifted from the basal drag to the longitudinal stress. This model of either no-slip or constant drag at the base will give rise to a very abrupt discontinuity at the surge front rather than a gradual one which would actually arise for laws like those shown in Figure 1. The nature of processes occurring at the gradual discontinuity will be preserved in the modeling and analysis of the abrupt discontinuity. At the gradual discontinuity there will be the large stresses of a stress concentration. At the abrupt discontinuity there will be the large stresses of a stress singularity. The kinematics of the transition in the abrupt discontinuity will be similar to the kinematics of the gradual transition.

It follows that the mechanics of such abrupt discontinuities are relevant to surging. The analysis of flow at such a boundary discontinuity has been considered by Hutter and Olunloyo (1980) but in the context of Newtonian viscosity. The transition involved was from no-slip to shear-free conditions. They found that a singularity in stress arises at the discontinuity as must be the case. In fact, the stress at such a discontinuity in any creeping solid or fluid must be singular. Rice and Rosengren (1968) and Hutchinson (1968[b]) (together denoted HRR) have analyzed such singularities for power-law materials including the special case of linear viscosity. Although the HRR analysis does not consider gravity-driven flows, we will show below that the analysis of the singular part of the stress near the discontinuity is the same whether the flow is gravity driven or not. The basic conclusion to be drawn is that there will be very large stresses developed at the discontinuity.

The infinite stresses will, of course, exceed any finite peak drag $\tau_{\mathrm{m}}$ of the more realistic sliding laws shown in Figure 1. Our point of view is that the actual stresses near the surge front arising from laws like those in Figure 1 can be considered to be a perturbation on the singularity solution we have outlined. That is, the processes of transition from high drag to low drag would take place in a relatively small zone near the discontinuity and would smooth out the singularity. However, away from the transition zone, the stresses would be relatively unperturbed from those of the singularity solution and as a result characterized by parameters of that solution. These outer stresses in turn would determine the behavior in the transition zone, meaning that the overall transition would be characterized by the singularity solution. A critical value of a parameter which characterizes the singular solution would then control the process. This parameter which will be discussed in more detail later will be referred to as $J$. A somewhat similar situation is accepted as a rationale for the validity of non-linear fracture mechanics in structural analysis. We propose adopting the same approach here and so we will consider in our modeling and analysis only the abrupt transition and the resulting singularity.

The abrupt transition is used here as a model for the gradual transition arising from laws like those shown in Figure 1. Since we believe that the transition as described by Kamb and others (1985) for Variegated Glacier would give rise to a law like (b) in Figure 1, the abrupt discontinuity is therefore an approximate model for that case. However, the abrupt discontinuity and the resulting singularity may be more precise when used as a model for the frozen-unfrozen divide in glaciers such as Trapridge Glacier (Clarke and others, 1984). An abrupt discontinuity of this type would give rise to a singular stress. In a relatively small region around the discontinuity, non-linear behavior of the ice, perhaps due to internal damage, would be activated. This would have the effect of eliminating the singularity. However, the effects would be present only very close to the discontinuity. The stresses farther afield would still be those of the singularity which would characterize all aspects of the discontinuity. Thus, the singularity model is one that we view as being relevant to basal discontinuities of a variety of types and we will use the model in the rest of the paper without reference to the character of the discontinuity.

We believe that it is the stress concentration at the surge front which causes the discontinuity to move down 
the glacier. The high stresses activate the process of transition at the discontinuity. The tunnel-closing mechanism suggested by Kamb and others for Variegated Glacier would be one example of a process of transition. For the case of Trapridge Glacier, we think that the frozen base must be ruptured somehow for the discontinuity to move and the processes of transition would be the rupturing mechanism. If the stress concentration is not sufficiently high or the high stresses are not spread over a large enough region, then the transition processes would not reach their critical extent and the discontinuity would not move. If, however, the stresses are high enough and spread out over a sufficiently large volume of ice, then the transition processes would change into those of lower drag. This would move the region of stress concentration and start to cause transition in the neighboring part of the glacier having high drag or a stuck base. If the critical conditions for transition can continue to be met, then the discontinuity will continue to move. Since we will be modeling the discontinuity as abrupt, the critical conditions will be phrased in terms of the parameter $J$ which characterizes the singular stresses there. When $J$ reaches a critical level, the discontinuity will move.

The effect would be like that which causes a slip surface or shear crack to propagate through over-consolidated clay and leads to the failure of embankments. A model for this, including the role of stress concentration or singularity in extending the failure, has been proposed by Palmer and Rice (1973). We will use certain aspects of their model and, in doing so, develop a framework for the mechanics of the propagating surge front.

\section{Surging model}

We are now in a position to give an overview of our surging model. From observations of Variegated Glacier by Kamb and others (1985), we see that the upper segment of the glacier was sliding rapidly for a couple of years before the surge year. This may have occurred because the critical stress for slow sliding in a law like those shown in Figure 1 was exceeded. The fast-sliding, low-drag region may have been confined originally to a small segment which later spread. It is possible that rapid sliding may occur locally in small sections of the glacier every season or it may be a permanent feature in certain areas. Our viewpoint is that it is very possible that such surging nuclei are common in many glaciers for a variety of reasons. In most years they are stabilized against growth by the prevailing state of the glacier. It should be remembered that, after a surge, the glacier is in a process of rebuilding and what may be stable one year may not be so in following years. Certainly, in Trapridge Glacier, the sliding region is present permanently in the temperate segment (Clark and others, 1984) and the discontinuity at the temperate-sub-polar interface is stable for many years.

Rebuilding proceeds and eventually the critical conditions are met for the propagation of the discontinuity. The discontinuity may move slowly at first and then accelerate, as seems to be the case in Variegated Glacier (Kamb and others, 1985). Such time effects may be due to the natural response of the viscous flow of the ice or may be due to temporal influences of the hydrology. We do not take these effects into consideration but concern ourselves with the question of whether the pre-existing surge nuclei can be stable. When they start to propagate, we show that in common situations and according to our assumptions, the rapid-sliding region will tend to grow and capture the whole glacier.

Thus a surge is initiated and will continue until the rapid sliding is terminated. This may be due to the loss of lubricating ground water, as seems to be the case in Variegated Glacier (Kamb and others, 1985), or it may be because the glacier thins to such an extent that the driving shear stress is insufficient to sustain the state of sliding. This would correspond to the basal shear stress falling below the minimum or the asymptote beyond point 1 in Figure 1. The glacier would now return to its quiescent state and rebuilding would commence. Now, any surge nucleus would be stable for several years. This would be so because the stresses generated at the discontinuity involved would be below the critical level due to the new shape of the glacier. Thus, a full-scale new surge would not be initiated for several more years.

Models similar to the one outlined above have been used previously, such as in the work of Lliboutry (1968). Similarly, Kamb and others (1985) have recognized the importance of sliding law non-linearities in their assessment of the surging of Variegated Glacier. However, we have considered the theoretical implications of the rapid sliding, the extending-compressing flow, and the discontinuities between slow- and fast-sliding regions. These aspects of the mechanics we have developed and incorporated into our model.

We now discuss the foundations of the mechanics which we believe must be understood for a complete modeling of surges. We will first discuss the stresses and velocities in the stuck parts (modeling slowly moving high-drag regions) and the sliding parts (modeling rapidly sliding relatively low-drag segments.) Following that we will consider the spreading of the sliding region and then a model surge, making comparisons with Medvezhy Glacier.

\section{STRESS AND VELOCITY IN THE GLACIER}

We will consider a glacier composed of an incompressible material obeying Glen's law. It is flowing down a valley with a slowly varying bed topography and we will use the $(x, y)$ coordinate system shown in Figure 3. For

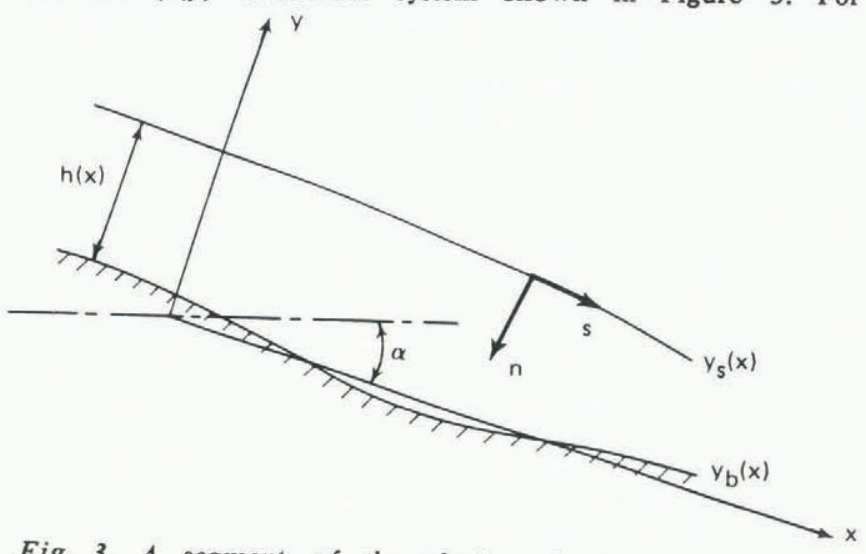

Fig. 3. A segment of the glacier showing the coordinate
system. system.

simplicity, we will consider only plane flow and an average bottom slope of $\tan \alpha$ which is $O(1)$, so that the valley is steep. A glacier on a gentle slope will behave in a similar manner.

Glen's law can be stated as

$$
\frac{\partial u}{\partial x}=\bar{B} \tau^{2} s_{x x}, \frac{\partial u}{\partial y}+\frac{\partial v}{\partial x}=2 \bar{B} \tau^{2} \sigma_{x y}
$$

where $\sigma_{i j}$ is the stress, $s_{x x}$ is the longitudinal deviatoric stress such that $s_{x x}=1 / 2\left(\sigma_{x x}-\sigma_{y y}\right),(u, v)$ are the $(x, y)$ components of velocity, and $x_{B}$ is a material parameter. $B$ should generally be temperature dependent but we will consider $\bar{B}$ to be a constant for simplicity. The equivalent stress $\tau$ is such that $\tau^{2}=3\left(s_{x x}^{2}+\sigma_{x y}^{2}\right)$. We will neglect
inertia.

The solution of the governing equations of momentum balance, flow law, and incompressibility with appropriate boundary conditions has been discussed by many authors including Fowler (1982), Hutter (1981, 1982, [ [ $\left.\left.{ }^{c} 1983\right]\right)$, Johnson and McMeeking (1984), and Nye (1969), to mention only a few. We will be interested in only the leading order terms in the solutions for a part of a glacier which is stuck which we consider to model regions of high drag and low sliding velocity. In addition, we consider a part which is sliding with drag $\tau_{s}$ to model regions of low drag, rapid sliding, and extensional or compressional flow. In general, it would be better if $\tau_{s}$ were a function of position, but we have taken it to be uniform for simplicity.

Non-sliding part

The leading order estimate of the shear stress in a stuck or non-sliding part of a glacier is 


$$
\sigma_{x y}=\rho g\left(y_{\mathrm{s}}-y\right) \sin \alpha
$$

where $\rho$ is the uniform ice density, $g$ is the gravitational constant, and $y_{\mathrm{S}}(x)$ is the $y$ position of the upper surface of the ice. The other stresses are

$$
\sigma_{x x}=\sigma_{y y}=\rho g\left(y-y_{\mathrm{s}}\right) \cos \alpha .
$$

The longitudinal deviatoric stress $s_{x x}$ is negligible. As discussed by Hutter (1981) and others, the first correction to Equations (2) and (3) in a regular perturbation scheme would have magnitudes $O(\delta)$ times the magnitudes in Equations (2) and (3), where $\delta$ is roughly the glacier thickness divided by the length and therefore small compared to unity. The velocity in a non-sliding part is

$$
u=\frac{3}{2} \bar{B}(\rho g \sin \alpha)^{3}\left[h^{4}-\left(y_{\mathrm{S}}-y\right)^{4}\right]
$$

where $h(x)=y_{\mathrm{s}}(x)-y_{\mathrm{b}}(x)$ is the glacier thickness. The velocity component $v$ is $O(\delta)$ times the magnitude of $u$ because $h^{\prime}(x), y_{\mathrm{S}}^{\prime}(x)$, and $y_{\mathrm{b}}^{\prime}(x)$ are all $O(\delta)$ compared to unity.

In an aside, it should be noted that there is a boundary layer near the free surface where $s_{x x}$ is more significant than $\sigma_{x y}$. This feature has been analyzed by Johnson and McMeeking (1984) and its influence on the analysis of longitudinal deviatoric stress has been discussed further by McMeeking and Johnson (1985). However, the layer can be detected only when one seeks higher-order corrections to Equations (2), (3), and (4).

\section{Sliding part}

The solution for this segment has been studied by McMeeking and Johnson (1985). In this part there must be the possibility of substantial extensional and compressional flows. This will give rise to rapid sliding away from the basal slip discontinuity. In addition, the longitudinal stress must be large enough that it bears some of the down-slope component of the weight. The down-slope component of the weight is the component parallel to the base and the amount transferred to the longitudinal stress is the difference from the basal drag, i.e. $\rho g h \sin \alpha-\tau_{s}$. In this part, the basal drag is not capable of adjusting itself to equate with the down-slope component of the weight. It is this fact which causes the longitudinal stresses to be large and determines the flow regime.

McMeeking and Johnson (1985) have found that the flow in this situation is to leading order a plug flow and so the longitudinal stress to leading order is independent of $y$,

$$
\sigma_{x x}=\sigma_{x x}(x) .
$$

In these circumstances, the shear stress can be found by integration of the momentum balance subject to the condition that the basal value equals the drag $\tau_{s}$, so

$$
\sigma_{x y}=\left(y_{\mathrm{b}}-y\right)\left(\mathrm{d} \sigma_{x x} / \mathrm{d} x+\rho g \sin \alpha\right)+\tau_{\mathrm{s}} .
$$

As usual, the stress $\sigma_{y y}$ balances the weight

$$
\sigma_{y y}=\rho g\left(y-y_{\mathrm{s}}\right) \cos \alpha
$$

but the longitudinal stress is an order of magnitude larger than $\sigma_{x y}$ and $\sigma_{y y}$. The boundary condition at $y=y_{s}$ which requires the surface to be shear-free provides a differential equation for $\sigma_{x x}$,

$$
\frac{\mathrm{d}}{\mathrm{d} x}\left(h \sigma_{x x}\right)+y_{b}(x) \sigma_{x x}=\tau_{\mathrm{s}}-\rho g h \sin \alpha
$$

and we will simplify this by taking $y_{\mathrm{b}}$ constant. Thus

$$
h \sigma_{x x}=\int_{x_{\mathrm{A}}}^{x}\left(\tau_{\mathrm{s}}-\rho g h \sin \alpha\right) \mathrm{d} x+h_{\mathrm{A}} \sigma_{x x}\left(x_{\mathbf{A}}\right)
$$

where $h_{\mathrm{A}}$ is $h$ at $x_{\mathrm{A}}$ as in Figure 2.

The velocities are such that

$$
\begin{gathered}
u=u(x, t), v=\left(y_{\mathrm{b}}-y\right) \mathrm{d} u / \mathrm{d} x \\
\mathrm{~d} u / \mathrm{d} x=(3 / 8) \bar{B} \sigma_{x x}^{3}
\end{gathered}
$$

and $u$ will generally be much larger than the velocity in the non-sliding part. The drag acts against the direction of sliding. Lastly, the shape of the glacier, i.e. the ice thickness $h=y_{\mathrm{s}}-y_{\mathrm{b}}$, is determined from mass conservation or, equivalently, the kinematic boundary condition on the velocity at the surface. We reiterate that, if the stresses are not as outlined above, then there can be no large compressive flows and as a result no compressive front as observed in surges.

At the intersection of a sliding part and a non-sliding part there will be a region straddling the intersection, approximately one glacier thickness in length, in which neither the solution in the sliding nor in the non-sliding part is valid. Strictly, we should solve the governing equations there and then match that solution to the sliding region solution on one side and the non-sliding region solution on the other side. Instead, we will match the two sections in an ad hoc way. The leading order velocity in a sliding region is generally several orders of magnitude larger than the velocity in a stuck part. Consequently, it is appropriate to set the velocity in the sliding part equal to zero at the join. Matching the velocities at higher orders will account for the relatively weak shearing flow in the stuck part. We have not performed this higher-order matching but we believe it can be completed successfully. This means that in the sliding region

$$
u=(3 / 8) \bar{B} \int_{x_{A}}^{x} \sigma_{x x}^{3} \mathrm{~d} x .
$$

If the sliding region is contained between two non-sliding regions as in Figure 2, then

$$
0=(3 / 8) \bar{B} \int_{x_{A}}^{x_{B}} \sigma_{x x}^{3} \mathrm{~d} x
$$

from which we can compute $\sigma_{x x}\left(x_{\mathrm{A}}\right)$ in Equation (9). Alternatively, if the sliding region has extended all the way to the snout at $l$ then we can take, as an approximation, $\sigma_{x x}=0$ there. Then

$$
h(x) \sigma_{x x}(x)=\int_{x}^{l}\left(\rho g h \sin \alpha-\tau_{s}\right) \mathrm{d} x
$$

which means that the excess of the down-slope weight over $\tau_{\mathrm{s}}(l-x)$ is supported by the longitudinal stress at $x$.

Generally, there will be a large longitudinal stress at the join between the sliding and non-sliding parts. This stress will be transmitted to the bed as a shear stress in the stuck part within approximately one glacier thickness from the join. In fact, the join between the sliding and non-sliding parts is a singularity for shear stress in the stuck region.

\section{Stresses at the discontinuity}

The singularity at the boundary-condition discontinuity is exactly of the type that arises in crack-tip fracture mechanics for structural materials (Rice and Rosengren, 1968; Hutchinson, 1968[b]). This singularity, known as the HRR singularity, dominates the near field and can be expressed as

$$
\sigma_{i j}=(J / r)^{1 /(n+1)} \sigma_{i j}(\theta, n)
$$

where $r$ and $\theta$ are polar coordinates from the point of discontinuity as shown in Figure 4 and the parameter $J$ to be discussed below scales the magnitude of the stress field. The function $\gamma_{i j}$ has been computed for pure shear with $n=3$ 


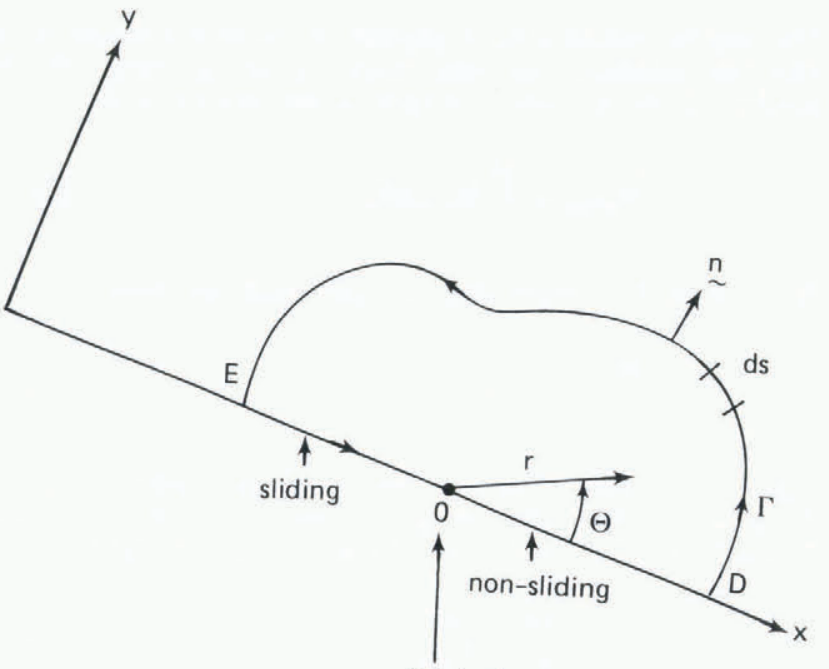

point of

discontinuity

Fig. 4. Boundary-condition discontinuity with contour I for $J$-integral.

by Hutchinson (1968[a]). The pure shear crack-tip calculations of Hutchinson provide the correct near-tip field because anti-symmetry and incompressibility lead to stationary velocities along the axis of anti-symmetry ahead of the crack. Hutchinson (1968[a]) was considering the case of non-linear elasticity rather than viscous flow but his result can be carried over by interpreting displacements as velocities, etc. The parameter $J$ which characterizes the stress field near the discontinuity is the $J$ integral defined as a generalization of the form used by Palmer and Rice (1973)

$$
J=2 \int_{\Gamma}(W-b \cdot u) \mathrm{d} y-\boldsymbol{n} \cdot \boldsymbol{\sigma} \cdot(\partial u / \partial x) \mathrm{d} s
$$

where $\boldsymbol{b}$ is the uniform (gravitational) body force per unit volume,

$$
W=\int_{0}^{\epsilon} \sigma_{i j} \mathrm{~d} \epsilon_{i j}
$$

where $\epsilon$ is the strain-rate and $\boldsymbol{n}$ is a unit vector on the contour $I$ from $D$ to $E$ to 0 as shown in Figure 4. When the base of the glacier is a straight line, the integral is path-independent.

The stresses and strain-rates near the discontinuity are characterized by the single parameter $J$. It follows that any process of rupture or break-down that takes place very near the discontinuity will be controlled by $J$. We propose that the criterion for spread of the sliding region is that $J$ equals or exceeds a critical value $J_{c}$. A similar criterion has been proposed for the growth of cracks in creeping metals at high temperature (Landes and Begley, 1976). Similarly, the deepening of crevasses may be controlled by $J$ and this will be discussed separately by McMeeking in future work. The path-independence of $J$ will be demonstrated in that paper.

At the discontinuity, there will be infinite stresses, or in reality very high stresses. Such infinite or very high stresses alone are not considered to be sufficient to operate the transition mechanism and cause the discontinuity to move. This can be understood if one considers discontinuities being acted upon by very low thrust. The stresses will still be infinite or very high near the discontinuity but one concludes that the discontinuity is not likely to move. Instead, we deduce that it is necessary for high stresses to be present over a critically large volume of ice for transition to take place. As $J$ increases, the high stresses near the singular point will spread over a larger volume of ice and eventually cover a sufficiently large volume. Depending on the situation, the processes involved may be the rupturing of ice or base (frozen base) or the creep closure of tunnels as suggested by Kamb and others (1985) for Variegated Glacier. Other mechanisms may operate in other cases. Thus, the critical value of $J$ would be related to the processes involved and would depend on how large a region of large stresses is required for the transition to occur and for the discontinuity to move. We will use the parameter in a phenomenological manner and not attempt to relate the critical value of $J$ to the processes involved.

This conludes our discussion of the foundations for the mechanics of surging. Further discussion of the issues of mechanics involved can be found in McMeeking and Johnson (1985) for the stress analysis and in Hutchinson (1968[a], [b]), Rice and Rosengren (1968), and the wealth of literature on non-linear fracture mechanics. We will now proceed to a description of our model for surging.

\section{A MODEL SURGE}

\section{Growth of the sliding region}

During most of the time the majority of the glacier base will be non-sliding and the shear stress at the base according to Equation (2) will be

$$
\tau_{\mathrm{b}}=\rho g h \sin \alpha .
$$

As discussed in the introduction, a surge nucleus may be a permanent, seasonal, sporadic or incipient feature of certain segments of the glacier. We think of a surge nucleus as a limited sliding region adjacent to or contained by stuck parts. Trapridge Glacier has a permanent nucleus in the form of a temperate region (sliding) up-stream from a sub-polar region (frozen stuck). Variegated Glacier may have a seasonal or sporadic nucleus. Seasonal and sporadic nuclei may occur because of annual cycles of melt-water flow. Incipient nuclei may be present in the sense that for some years conditions to form the nucleus may not be met because of the glacier state. Then, after some rebuilding, the basal shear stress is sufficiently high locally to cause more rapid sliding and a limited surge nucleus is formed. We have no stronger evidence for our suggestion of surge nuclei. But we would claim that the inhomogeneity of glaciers is such that seasonal, sporadic or incipient rapidsliding regions are entirely possible. They may be very limited, but conditions for the initiation of surging would be those that determine whether the nucleus spreads rather than those that determine whether they exist in a given case. If nuclei are not present, our surge model is without validity. That situation would be remedied by considering more detailed aspects of what causes low-velocity sliding to accelerate at least locally.

Given the existence of a surge nucleus, we now consider the question of whether it will spread. Consider the nucleus to be the segment $\mathbf{A B}$ in Figure 2. This region is sliding rapidly and the longitudinal stress there is given by Equation (9) subject to boundary condition in Equation (13) Part of the weight of $\mathbf{A B}$ is no longer borne by the basal shear stress because the down-slope component exceeds the net drag. This excess has now been thrust on to the neighboring non-sliding parts and this will cause the basal shearstress singularities as discussed previously. The discontinuity will move and the sliding region will spread if $J$ at the discontinuity exceeds the critical level.

It is likely that a sliding region like $\mathrm{AB}$ would be quite short to begin with, i.e. less than one glacier thickness. The model would be characterized better if calculations of $J$ for short sliding regions were available. Calculating $J$ for the edges of sliding regions shorter than or comparable to $h$ is quite difficult and would require numerical methods. Only when the sliding region has spread to somewhat longer than $h$ can a leading order estimate be obtained easily. We will assume that such a surge nucleus exists. The details of the calculation of $J$ for the
discontinuities at either end of a sliding region like AB are 
given in the Appendix. When $\mathbf{A B}$ is longer than $h$, the value of $J$ at the discontinuity at $B$ is

$$
J_{\mathrm{B}}=3 \bar{B}_{\mathrm{B}}\left(\sigma_{x x}\left(x_{\mathrm{B}}\right)\right)^{4} / 16
$$

to leading order and there will be an equivalent value at $\mathbf{A}$. This nucleus will spread if $J_{\mathbf{A}}$ or $J_{\mathbf{B}}$ equals or exceeds the critical value $J_{C}$ and will be stable otherwise. As the region spreads, either $\sigma_{x x}\left(x_{\mathrm{A}}\right)$ or $\sigma_{x x}\left(x_{\mathrm{B}}\right)$, or both will increase in magnitude where $A$ and $B$ always define the limits of the current sliding region. If the critical value $J_{c}$ is fairly uniform in the glacier, the lower extremity B will move down to the snout of the glacier at $x=l$. The upper limit A may travel to an ice reservoir or be blocked by some basal feature at which $J_{c}$ is high. A third possibility is that the large longitudinal stresses will break off the surging part. We consider the final position of the upper limit to be at $x=0$.

The rate of extension of the sliding region would probably be controled by the time necessary to incubate damage, e.g. tunnel closing around the boundary-condition discontinuity. However, it is clear from Equation (9) that the lower discontinuity at $\mathrm{B}$ would move down the glacier as a compression front as observed in Variegated Glacier by Kamb and others (1985). The upper discontinuity would move up the glacier as a tensile front. Of course, if the surge nucleus is originally near the top of the glacier, then the moving tensile front would not exist for long. However, a tensile region is explicit in our treatment of the model. If the ice is incapable of sustaining the tension that develops, then the surging part would break off. The resulting static imbalance would lead to unsteady motion of the glacier until surging terminates. We have not analyzed this possibility, although it may be important. Presumably, the drag forces involved would still be sufficiently high to keep the velocity of the surging parts to relatively low levels.

All or parts of the glacier are now sliding rapidly and stretching of the ice mass occurs. As discussed previously, we introduce into our model a surge termination in a phenomenological way. The surge may terminate due to loss of lubricating water or because of seasonal changes. The termination may occur first near the top and move down the glacier, as seems to be the case in Variegated Glacier or it may occur simultaneously throughout the glacier. The glacier returns to its quiescent state and the surge nucleus is once more stable. This will be so if the relevant surge nucleus is in a region of the glacier which has thinned during surging - generally, in the upper part of the surging segment. This can be seen from Equation (18) where the thickness enters directly. In addition, the total weight of the surge nucleus would be less than before and so the longitudinal stress $\sigma_{x x}$ at the discontinuity would be lower than before. The surge nucleus would be stable until the height returns approximately to pre-surging levels due to rebuilding of the glacier. Note also that the inverse viscosity parameter $\bar{B}$ enters Equation (18) making it possible that seasonal fluctuations of ice rheology play a role in determining the value of $J$ at a discontinuity.

\section{Evolution of the surging glacier}

The shape change during surging should be calculated while the surge fronts move down the glacier and until surging terminates. However, for simplicity, we will calculate the evolution by assuming that no shape change occurs while the surge fronts are moving through the glacier. Once a full surge part is established, the shape change of stretching and compression, and thinning and thickening occurs. This modeling is deficient, especially for Variegated Glacier where a contained surge region moves down through the glacier and surging terminates shortly after the surge region nears the snout. Our assumptions are equivalent to saying that the surge fronts move more rapidly than motions controled entirely by ice rheology which may be the case in certain glaciers.

At this stage in our model a lengthy segment of the glacier is sliding rapidly unconstrained at the snout. The complete solution during this period requires the solution of Equation (8) for the stress $\sigma_{x x}$, along with the determination of the velocity field and the glacier shape from Equation (11) and the equation for mass conservation.
For ease of calculation, it appears to be most convenient to cast the equation for mass conservation in terms of the glacier volume between a postion $x$ and the snout $l$,

$$
V(x, t)=\int_{x}^{l} h(\hat{x}, t) \mathrm{d} \hat{x} .
$$

In terms of $V$, conservation of mass takes the form

$$
\frac{\partial V}{\partial t}=u(x, t) h(x, t)
$$

where we have neglected the generally small effect of accumulation and ablation during the surge period. Lastly, noting that $\partial V / \partial x=-h$, we can write Equation (20) as

$$
\frac{\partial V}{\partial t}+u \frac{\partial V}{\partial x}=0
$$

For simplicity, we will assume that the bed of the glacier has a uniform slope, i.e. $y_{b}$ vanishes, and then the four equations for the four unknowns $V, h, \sigma_{x x}$, and $u$ which fully determine the motion and stress field for the surging glacier are

$$
\begin{gathered}
\frac{\partial V}{\partial t}+u \frac{\partial V}{\partial x}=0, \\
\frac{\partial u}{\partial x}=\frac{3}{8} \bar{B} \sigma_{x x}^{3}, \\
\sigma_{x x} \frac{\partial V}{\partial x}=\int_{x}^{l}\left[\tau_{s}-\rho g h \sin \alpha\right] \mathrm{d} \hat{x} \\
h=-\frac{\partial V}{\partial x} .
\end{gathered}
$$

For illustration purposes, consider the case when the basal shear stress is such that it supports a fraction $k$ of the down-slope component of the glacier weight, i.e. $\tau_{\mathrm{s}}=$ $k \rho g h \sin \alpha$. In this case, Equation (24) gives

$$
\sigma_{x x} \frac{\partial V}{\partial x}=(k-1) \rho g \sin \alpha V,
$$

and therefore

$$
\frac{\partial(\ln V)}{\partial x}=\frac{\beta}{\sigma_{x x}} \text {, where } \beta=(k-1) \rho g \sin \alpha .
$$

In addition, by dividing Equation (22) by $V$ and then by differentiating it with respect to $x$, we can write Equation (22) as

$$
\frac{\partial}{\partial t}\left[\frac{\partial}{\partial x}(\ln V)\right]+u \frac{\partial}{\partial x}\left[\frac{\partial}{\partial x}(\ln V)\right]=-\frac{\partial u}{\partial x} \frac{\partial}{\partial x}(\ln V) .
$$

Now, combining equations (23), (27), and (28), we obtain the following equation for the stress

$$
\frac{\partial \sigma_{x x}}{\partial t}+u \frac{\partial \sigma_{x x}}{\partial x}=\frac{3}{8} \bar{B} \sigma_{x x}{ }^{4},
$$

which is a non-linear kinematic wave equation. Using the initial particle position $\boldsymbol{X}$ and time as independent variables in place of the spatial variable $x$ and time, this equation is 
generally written as an evolution equation along the characteristic curves, i.e.

$$
\frac{\mathrm{d} \sigma_{x x}}{\mathrm{~d} t}=\frac{3}{8} \bar{B} \sigma_{x x}
$$

on curves given by:

$$
\frac{\mathrm{d} x}{\mathrm{~d} t}=u \text { where } x=X \text { at } t=0 .
$$

In this case, the characteristic curves determined from Equation (31) are simply the trajectories of the material particles $x=x(X, t)$ where $X$ is the initial position of a material particle. This is equivalent to using a Lagrangian formulation as opposed to an Eulerian formulation.

The solution to Equation (30) for the stress $\sigma_{x x}$ of a material particle in terms of the initial stress field $\sigma_{0}$ is

$$
\sigma_{x x}=\frac{\sigma_{0}}{\left[1-\frac{9-}{8} B \sigma_{0}^{3} t\right]^{1 / 3}}
$$

where $\sigma_{0}$ is given in terms of the initial glacier shape by

$$
\sigma_{0}=\sigma_{x x}(X, t=0)=\frac{(1-k) \rho g \sin }{h(X, 0)} \alpha \int_{X}^{l_{0}} h(\hat{X}, 0) \mathrm{d} \hat{X},
$$

and $l_{0}$ is the initial snout position. The stress at a fixed point $x$ in space is found from Equation (32) using the relation between $x$ and $X$ obtained by integrating Equation (31)

$$
x=X+\int_{0}^{t} u(x, \hat{t}) \hat{\mathrm{d} t} .
$$

Here $u$ is determined from the stress-strain-rate relation in Equation (23),

$$
\frac{\partial u}{\partial x}=\frac{3-}{8} \sigma_{x x}^{3}=\frac{3-}{8}\left\{\frac{\sigma_{0}^{3}}{1-\frac{9 \bar{B} \sigma_{0}^{3} t}{8}}\right\} .
$$

To conveniently use Equation (35), however, we must first change variables from $x$ and $t$ to $X$ and $t$ as follows

$$
\begin{aligned}
\frac{\partial u}{\partial x} & =\frac{\partial u}{\partial X} \frac{\partial X}{\partial x}=\frac{\partial u}{\partial X}\left\{1-\frac{\partial}{\partial x} \int_{0}^{t} u(x, \hat{t}) \hat{\mathrm{d} t}\right\} \\
& =\frac{\partial u}{\partial X}\left\{1-\int_{0}^{t} \frac{3}{8} B \sigma_{x x}^{3} \hat{\mathrm{d} t}\right\},
\end{aligned}
$$

so that we have from Equation (35)

$$
\frac{\partial u}{\partial X}=\frac{1}{3} \frac{\frac{9}{8} \bar{B} \sigma_{0}^{3}}{\left[1-\frac{9}{8} B \sigma_{0}^{3} t\right]\left[1+\frac{1}{3} \ln \left[1-\frac{9}{8} \bar{B} \sigma_{0}^{3} t\right]\right]} .
$$

This can now be integrated to determine $u(X, t)$ which in turn can be substituted into Equation (34) to determine the position $x$ of a particle which started at a location $X$ at $t=$ 0 . Using Equation (36), we find for Equation (34)

$$
x=X+\frac{1}{3} \int_{0}^{t} \int_{0}^{X} \frac{\frac{9}{8} \bar{B} \sigma_{\mathrm{o}}^{3}}{\left[1-\frac{9}{8} \bar{B} \sigma_{0}^{3} \hat{t}\right]\left[1+\frac{1}{3} \ln \left(1-\frac{9}{8} \bar{B} \sigma_{0}^{3} \hat{t}\right)\right]} \mathrm{d} \hat{X} \hat{\mathrm{d}} .
$$

By interchanging the order of integration, this can be simplified to

$$
x=X-\int_{0}^{X} \ln \left[1+\frac{1}{3} \ln \left(1-H^{3}(\hat{X}) T\right)\right] \mathrm{d} \hat{X}
$$

where we have used Equation (33) and we define

$$
H(X)=\int_{X}^{l_{0}} h(\hat{X}, 0) \mathrm{d} \hat{X} / l_{0} h(X, 0)=V(X, 0) / l_{0} h(X, 0) .
$$

In Equation (37) $T$ is a dimensionless time given by

$$
T=\frac{9}{8} \bar{B}\left[(1-k) l_{\mathrm{o}} \rho g \sin \alpha\right]^{3} t .
$$

Lastly, from Equations (25), (26), and (32) we find the ice thickness to be

$$
h(X, t)=h(X, 0)\left[1-\frac{9}{8} \bar{B} \sigma_{0}^{3} t\right]^{-1 / 3}
$$

$$
=h(X, 0)\left[1-H(X)^{3} T\right]^{1 / 3} \text {. }
$$

A comparison between theory and observation was made using the data given by Dolgushin and Osipova (1975) for the surge of Medvezhy Glacier which occurred in 1963. From the figures presented by Dolgushin and Osipova, data for the shape of the surging glacier were extracted using a Hewlett-Packard $7470 \mathrm{~A}$ plotter and digitizing sight. The figures were enlarged to improve the resolution of the data. Using the initial configuration of Medvezhy Glacier in 1963 , immediately prior to the surge, we computed the evolution of the glacier shape from our model. Results for three equal time intervals are shown in Figure 5. In addition, in Figure 6 we compared the observed post-surge shape to the shape calculated in our model when the distance the snout had advanced was coincident with that of the actual glacier. The agreement is quite remarkable. Some of the discrepancies can be attributed to the fact that we have assumed a uniform bed slope which is not quite accurate for Medvezhy Glacier and also to the fact that we have used a very simple form for the basal shear stress $\tau_{\mathrm{s}}$. One feature to note concerning the present solution is the singularity in the stress field which occurs at a finite

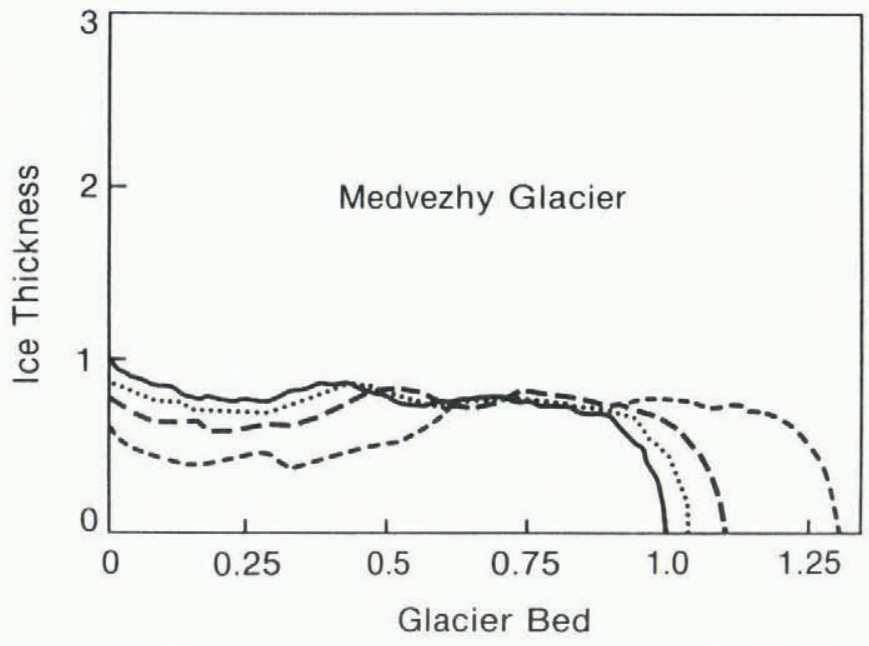

Fig. 5. Calculated surging motion of Medvezhy Glacier starting with the observed initial configuration. Glacier profiles are shown for four values of $T: 0,-; 0.58$, ... ; 1.16, - - ; 1.74, - - ; the glacier-bed axis and ice thickness are non-dimensionalized by the initial surge length $l_{o}$ and initial thickness at $x=0$, respectively. 


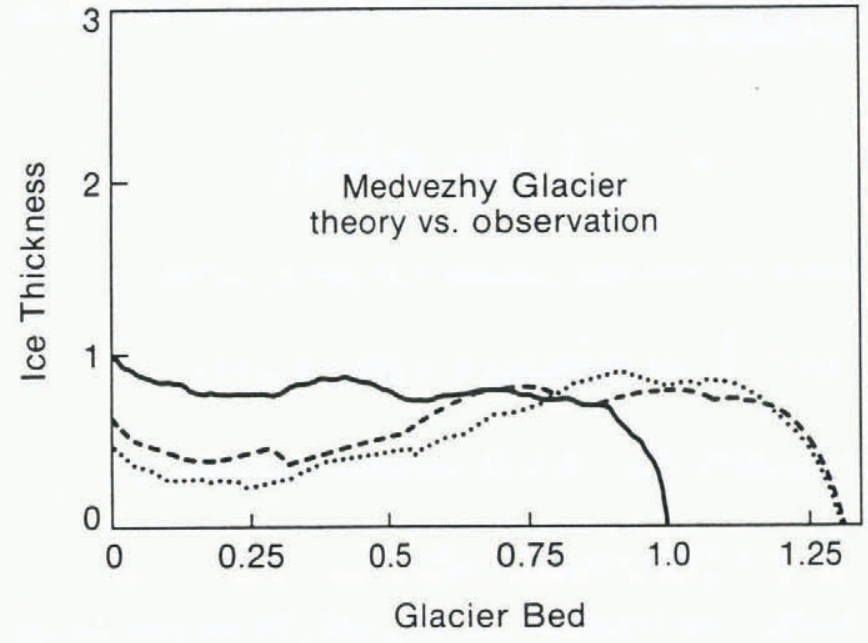

Fig. 6. Comparison of the final glacier profile between theory $\left(--_{-}\right)$and observation $(\cdots)$ for the surge of Medvezhy Glacier. The initial configuration is also shown (-). The glacier-bed axis and ice thickness are non-dimensionalized by the initial surge length $l_{o}$ and initial thickness at $x=0$, respectively.

time (see Equation (32)). This is a fairly common characteristic for non-linear equations of the type considered here, i.e. Equation (29). Furthermore, note that the velocity field is determined from the stress field, and, consequently, it is also singular. This can be seen in Figure 7 where we have plotted the position of the snout of Medvezhy Glacier versus time. The singularity in the stress field occurs at $T=1 /\left(H^{3}\right)_{\max }$, and corresponds to the glacier thickness disappearing at some point as can be seen from Equation (38). The singularity in the velocity field actually precedes this by a small amount and is found to occur at $T=\left(1-\mathrm{e}^{-3}\right) /$ $\left(H^{3}\right)$. The singularity occurs partly because of the lack of inertial effects in our model. The physical significance of the approach in time to this singularity might be interpreted as follows. Since there is no limiting stress level or velocity, the velocity and longitudinal stress of a surging glacier will steadily increase and will eventually reach a point in time when the basal water system which is responsible for maintaining the high sliding velocities will be disrupted by the large strain-rates present. This will result in a drag greater than the down-slope component of the weight and the basal velocity will return to a level typical of the non-surge period when the glacier is essentially stuck to the bed. A

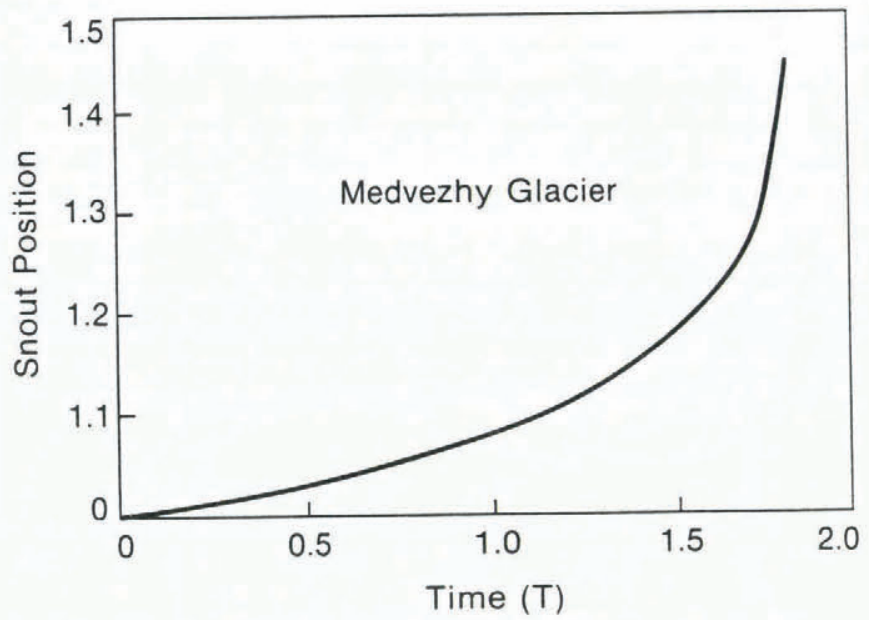

Fig. 7. The calculated position of the snout as a function of time for Medvezhy Glacier. The position of the snout is non-dimensionalized by the initial snout position $l_{o}$ and

$$
T=\frac{9}{8}-\bar{B}\left[(1-k) l_{0} \rho g \sin \alpha\right]^{3} t
$$

is a dimensionless time. new surge will not commence until the glacier, which has been thinned by the surge, has had sufficient time to build up once again and re-develop its basal water network. Ultimately, the down-slope component of the weight will again exceed critical levels in surge nuclei and a new surge will be initiated.

From the present analysis, we can estimate the ratio of the recovery time (i.e. the time it takes the glacier to be rebuilt) to the surge duration time. We assume that the recovery time is the time it takes for the inflow at $x=0$ plus the accumulation between $x=0$ and $l$ to equal the volume depleted during the surge. The volume depleted by the surge is the volume of ice which passed the original snout position $l_{0}$. From our calculations for Medvezhy Glacier, we find this to be equal to $Q_{\mathrm{s}} h_{\mathrm{o}} l_{\mathrm{o}}$ where $h_{\mathrm{o}}$ is the maximum ice thickness and $Q_{\mathrm{s}}=0.1911$. For simplicity we assume that the net accumulation or ablation between $x=0$ and $l_{0}$ during the recovery period is equal to $Q_{\mathrm{A}} h_{0} l_{0}$ where $Q_{A}$ is a constant. In the lower part of the glacier where the surge took place we expect spring and summer melting to exceed winter snowfall, so that the material carried beyond $x=l_{0}$ by the surge would be melted away rather quickly. In any case, the mass balance defining the recovery period is

$$
\int_{0}^{\Delta t} \frac{6}{5} \bar{B}(\rho g \sin \alpha)^{3} h^{5}(0, t) \mathrm{d} t+Q_{\mathrm{A}} h_{\mathrm{o}} l_{\mathrm{o}}=Q_{\mathrm{s}} h_{0} l_{0} .
$$

Consequently, the time to replace the volume, i.e. the recovery time, is

$$
\Delta t_{\mathrm{r}}=\frac{\left(Q_{\mathrm{S}}-Q_{\mathrm{A}}\right) h_{0} l_{0}}{\frac{6}{5} B(\rho g \sin \alpha)^{3} \overline{\left.h^{5}\right]}}
$$

where an overbar on $h^{5}$ represents a time average in the time interval $t=0$ to $\Delta t_{\mathrm{r}}$.

On the other hand, the surge duration can be estimated from our calculation for Medvezhy Glacier. We found that the position of the glacier snout coincided with the observed position when the time $T=1.74$, i.e.

$$
{ }_{8}^{9-}(\rho g \sin \alpha)^{3}(1-k)^{3} l_{0}^{3} \Delta t_{\mathrm{s}}=1.74
$$

where $\Delta t_{\mathrm{s}}$ is the surge duration time. Therefore, the ratio $\Delta t_{\mathrm{r}} / \Delta t_{\mathrm{s}}$ is found to be

$$
\frac{\Delta t_{\mathrm{r}}}{\Delta t_{\mathrm{S}}}=\frac{15}{16} \frac{\left(Q_{\mathrm{S}}-Q_{\mathrm{A}}\right)}{1.74 \gamma}(1-k)^{3}\left[\frac{l_{0}}{h_{\mathrm{o}}}\right]^{4}
$$

where $y=\overline{\left[\left(h / h_{0}\right)^{5}\right]}$ is the time average over the time interval $t=0$ to $\Delta t_{\mathrm{r}}$. Although it is difficult to use Equation (41) directly, it reveals the relevant physical parameters which control the surge cycle. Furthermore, we can use Equation (41) to estimate the parameter $k$ which is a measure of the basal shear stress. For Medvezhy Glacier, $l_{\mathrm{o}}=6000 \mathrm{~m}, h_{\mathrm{o}}=200 \mathrm{~m}$, and the observed duration times are: $\Delta t_{\mathrm{r}}=12$ years; $\Delta t_{\mathrm{s}}=2$ months. In addition, from our calculations we found $Q_{\mathrm{s}}=0.1911$ and, if we further assume that accumulation is responsible for replacing half of the surged volume, i.e. $Q_{\mathrm{A}}=1 / 2 Q_{\mathrm{S}}$, and we take $y=1$, then we have the following estimate for $k$,

$$
k=1-\left[19.4 \frac{\Delta t_{\mathrm{r}}}{\Delta t_{\mathrm{S}}}\right]^{1 / 3}\left[\frac{h_{0}}{\mathrm{U}_{0}}\right]^{4 / 3} \approx 0.88
$$

Recalling the definition of $k$, this indicates that during the surge of Medvezhy Glacier $88 \%$ of the down-slope component of the weight was being carried by the basal shear stress, the remainder being supported by the longitudinal stress. 
Examining Equation (41) more generally, we see that as $k \rightarrow 1$ (i.e. the basal shear stress supporting all of the weight), $\Delta t_{\mathrm{r}} / \Delta t_{\mathrm{s}} \rightarrow 0$ or $\Delta t_{\mathrm{s}} \rightarrow \infty$, and there is no noticeable surge since the motion is occurring so slowly. Furthermore, $\Delta t_{\mathrm{r}} / \Delta t_{\mathrm{s}}$ is a maximum and the surge is the most dramatic (since $\Delta t_{\mathrm{s}}$ is a minimum) when we have perfect slip, i.e. $k \rightarrow 0$.

\section{DISCUSSION}

The surge model discussed in this paper is highly idealized. However, it has the virtue of bringing out important features and explaining some basic observations of surges as discussed by Kamb and others (1985), Paterson (1981), and Dolgushin and Osipova (1975). These are that a compression front travels down the glacier, that the ice velocities during a surge are an order of magnitude larger than the non-surging values, and a general description of the evolving glacier shape during a surge.

However, the details are bound to be affected by the use of a more realistic sliding law. This would tend to smooth out the boundary discontinuity at the base between rapidly sliding segments and slowly moving parts. However, we believe that the phenomenon of the spreading of this discontinuity would be similar to the one we have discussed. A more realistic sliding law would also make our $J$ criterion more difficult to apply. Again, we think that our simplified description captures the essence of the phenomena. In addition, the inflected law of type (a) in Figure 1 may lead to a rapidly sliding region in which the down-slope weight is supported to leading order by the basal shear stress. The basal velocities in this region would lie to the right of $u_{\mathrm{b}}^{2}$ in Figure 1. However, this region would be adjacent to a section in which the basal velocities would lie between $u_{\mathrm{b}}^{1}$ and $u_{\mathrm{b}}^{2}$ and so the down-slope component of weight there would be partly supported by the longitudinal stress gradient. This would thrust weight on to more slowly moving sections and tend to destabilize them in the manner we have discussed. Thus the process of spreading of the rapid-sliding region would take place in a way similar to the situation described in our model. However, the smoother nature of the sliding law would mean that spreading would take place more slowly.

The rapid-sliding region would spread all the way down to the snout in a surge in general so that the snout can move substantial distances during the surge. The question of how far the upper limit of the sliding region can move is more difficult. Since more and more stress is transferred to the remaining stuck part as the sliding segment extends, it seems possible that by our model the sliding region could extend eventually all the way up to the top of the glacier, to an ice divide or reservoir. This seldom occurs in practice, with the surging part usually confined to a segment near the snout (Paterson, 1981). The answer may lie in the limited tensile strength of the ice. This would led to fracture of the ice at the upper end of the rapidly sliding region rather than spreading of the destabilized part. This fracturing has been observed in Medvezhy Glacier (Paterson, 1981). Effectively, all the down-slope component of unbalanced weight would be thrown on to the lower margin of the sliding region. When this breaks through to the snout, the unbalanced part of the down-slope weight would cause acceleration of the ice mass which would continue until the end of surging, if the sliding law is like (b) in Figure 2. If the law is like (a) in Figure 1, the acceleration would continue until all of the surging part was sliding at a speed greater than $u_{b}^{2}$ where a quasi-static balance can re-occur.

It is important to note that the general framework of the model we have proposed does not require the basal shear stress to fall dramatically everywhere in the surging part. The weakened segment could be relatively small when a surge commences. However, the transfer of the down-slope weight from the base in the weakened segment to the neighboring parts would cause relatively large forces to be applied to the unweakened sections. These large forces would develop enormous shear stresses at the base in the unweakened segment and could cause it to slide rapidly or rupture, even if it is relatively strong. It follows that the surge could be set off by a limited segment in which the basal shear stress exceeds a critical value and initiates rapid sliding. In years of quiescence, the surge nucleus could exist in a stable manner. The surge year is the one in which the glacier is finally rebuilt after a previous surging episode to the extent that a big enough segment slides rapidly, and enough down-slope weight is transferred from the base to the neighboring parts of the glacier to destabilize them.

\section{ACKNOWLEDGEMENTS}

This work was carried out while the authors were supported by the National Science Foundation under grants MEA 82-11018 (R.M.M.) and MEA 83-11495 (R.E.J.). One of us (R.M.M.) was also supported by a U.K. Science and Engineering Research Council Senior Visiting Fellowship at the University of Cambridge.

\section{REFERENCES}

Budd, W.F. 1975. A first simple model for periodically self-surging glaciers. Journal of Glaciology, Vol. 14, No. 70 , p. $3-21$.

Clarke, G.K.C., and others. 1984. Flow, thermal structure, and subglacial conditions of a surge-type glacier, by G.K.C. Clarke, S.G. Collins, and D.E. Thompson. Canadian Journal of Earth Sciences, Vol. 21, No. 2, p. $232-40$.

Dolgushin, L.D., and Osipova, G.B. 1975. Glacier surges and the problem of their forecasting. [Union Géodésique et Géophysique Internationale. Association Internationale des Sciences Hydrologiques. Commission des Neiges et Glaces.] Symposium. Neiges et glaces. Actes du colloque de Moscow, août 1971, p. 292-304. (IAHS-AISH Publication No. 104.)

Fowler, A.C. 1982. Waves on glaciers. Journal of Fluid Mechanics, Vol. 120, p. 283-321.

Frost, H.J., and Ashby, M.F. 1983. Deformation maps. Oxford, etc., Pergamon Press.

Hutchinson, J.W. 1968[a]. Plastic stress and strain fields at a crack tip. Journal of the Mechanics and Physics of Solids, Vol. 16, p. 337-47.

Hutchinson, J.W. 1968[b]. Singular behaviour at the end of a tensile crack in a hardening material. Journal of the Mechanics and Physics of Solids, Vol. 16, p. 13-31.

Hutter, K. 1981. The effect of longitudinal strain on the shear stress of an ice sheet: in defence of using stretched coordinates. Journal of Glaciology, Vol. 27, No. 95, p. 39-56.

Hutter, K. 1982. Dynamics of glaciers and large ice masses. Annual Review of Fluid Mechanics, Vol. 14, p. 87-130.

Hutter, K. [ ${ }^{\mathrm{c}}$ 1983.] Theoretical glaciology; material science of ice and the mechanics of glaciers and ice sheets. Dordrecht, etc., D. Reidel Publishing Company/Tokyo, Terra Scientific Publishing Company.

Johnson, R.E., and McMeeking, R.M. 1984. Near-surface flow in glaciers obeying Glen's law. Quarterly Journal of Mechanics and Applied Mathematics, Vol. 37, Pt. 2, p. 273-91.

Kamb, W.B., and others. 1985. Glacier surge mechanism: 1982-1983 surge of Variegated Glacier, Alaska, by W.B. Kamb [and 7 others]. Science, Vol. 227, No. 4686, p. 469-79.

Landes, J.E., and Begley, J.A. 1976. A fracture mechanics approach to creep crack growth. (In Mechanics of crack growth. Philadelphia, American Society for Testing and Materials, p. 128-48. (ASTM STP 590.))

Lliboutry, L. 1968. General theory of subglacial cavitation and sliding of temperate glaciers. Journal of Glaciology, Vol. 7 , No. 49 , p. 21-58.

McMeeking, R.M., and Johnson, R.E. 1985. On the analysis of longitudinal stress in glaciers. Journal of Glaciology, Vol. 31, No. 109, p. 293-302.

Morland, L.W., and Johnson, I.R. 1980. Steady motion of ice sheets. Journal of Glaciology, Vol. 25, No. 92, p. 229-46. 
Nye, J.F. 1969. The effect of longitudinal stress on the shear stress at the base of an ice sheet. Journal of Glaciology, Vol. 8, No. 53, p. 207-13.

Palmer, A.C., and Rice, J.R. 1973. The growth of slip surfaces in the progressive failure of over-consolidated clay. Proceedings of the Royal Society of London, Ser. A, Vol. 332, No. 1591, p. 527-48.

Paterson, W.S.B. 1981. The physics of glaciers. Second edition. Oxford, etc., Pergamon Press. (Pergamon International Library.)

Raymond, C.F. 1980. Temperate valley glaciers. (In Colbeck, S.C., ed. Dynamics of snow and ice masses. New York, Academic Press, p. 79-139.)

Rice, J.R., and Rosengren, G.F. 1968. Plane strain deformation near a crack tip in a power-law hardening material. Journal of the Mechanics and Physics of Solids, Vol. 16, p. 1-12.

Roscoe, K.H. 1970. Influence of strains in soil mechanics. Géotechnique, Vol. 20, No. 2, p. 129.

Shoemaker, E.M., and Morland, L.W. 1984. A glacier flow model incorporating longitudinal deviatoric stresses. Journal of Glaciology, Vol. 30, No. 106, p. 334-40.

\section{APPENDIX}

\section{CALCULATION OF $J$ AT A DISCONTINUITY}

For simplicity, $J$ will be calculated to leading order at the discontinuity $B$ when the glacier has uniform thickness $h$. The contour for this calculation will be FGHKB as shown in Figure 8. It is possible to estimate $J$ for a non-uniformly thick glacier. The algebra is more extensive

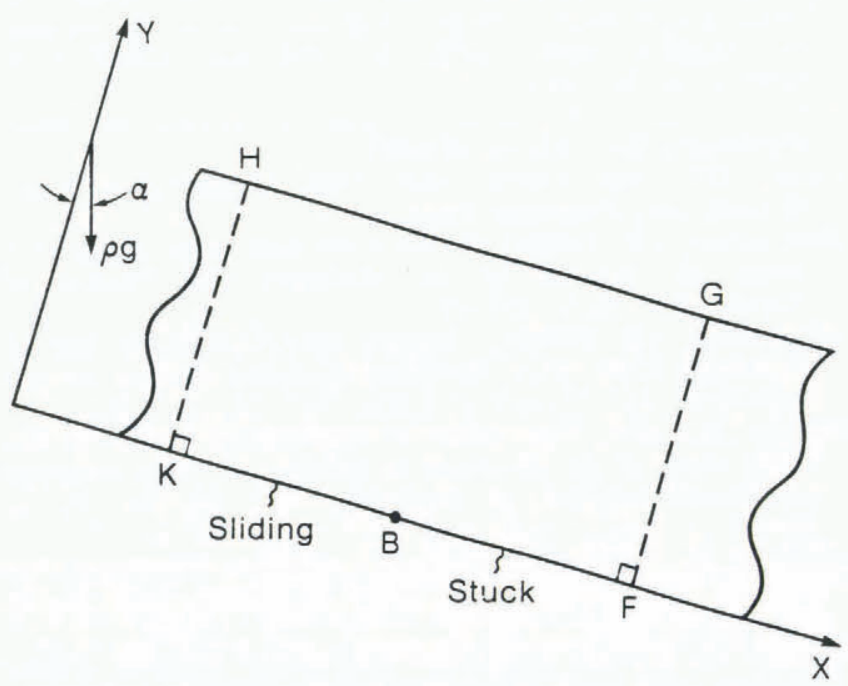

Fig. 8. Contour for the calculation of $J$ at B.

in that case but the leading-order estimate is the same as that for the uniform glacier.

For the calculation to be simple, it is necessary for the segments FG and HK to be well away from B so that the appropriate leading-order estimates for stress dominate the respective region. Recalling that

$$
J=2 \int_{\text {FGHKB }}(W-\rho g \sin \alpha u+\rho g \cos \alpha v) \mathrm{d} y-
$$

$$
-n \cdot \sigma \cdot(\partial u / \partial x) \mathrm{d} s,
$$

we now consider the contributions from the various segments of the contour. We will start with GH. On this line, $\mathrm{d} y=0$ and the traction $n \cdot \sigma=0$, so there is no contribution. On HK the solution is dominated by longitudinal stress as outlined in Equations (5)-(11) and so we will dispense with any term lacking $\sigma_{x x}$ in it. It follows that $W=(9 / 32) \bar{B} \sigma_{x x}^{4}$ and $n \cdot \sigma \cdot(\partial u / \partial x)=-\sigma_{x x}$ $(\partial u / \partial x)$. Note also that $v$ is an order of magnitude less than $u$ and for a steep glacier we can always neglect $\rho g \cos \alpha v$ compared to $\rho g \sin \alpha u$. As a result of the fact that $\mathrm{d} s=$ $-\mathrm{d} y$ on HK, the leading-order contribution to $J$ from this part of the contour is

$$
J_{\mathrm{HK}}=2 \int_{\mathrm{K}}^{\mathrm{H}}\left((3 / 32) \bar{B} \sigma_{x x}^{4}+\rho g \sin \alpha u\right) \mathrm{d} y .
$$

Since $\sigma_{x x}$ and $u$ are functions of $x$ alone, Equation (A-2) becomes

$$
J_{\mathrm{HK}}=(3 / 16) \bar{B}\left(\sigma_{x x}\left(x_{\mathrm{K}}\right)\right)^{4} h+2 \rho g h \sin \alpha u\left(x_{\mathrm{K}}\right) .
$$

On segment FG, the solution is dominated by shear and hydrostatic stress as given in Equations (2) and (3). Consequently, $W=(9 / 2) \bar{B} \sigma_{x y}^{4}$ to leading order there and $n \cdot \sigma \cdot(\partial u / \partial x)=\sigma_{x x} \partial u / \partial x+\sigma_{x y} \partial v / \partial x$. This last term is smaller in magnitude than $\bar{B} \sigma_{x y}^{4}$ on FG and it can be dropped immediately. It follows that the contribution from FG is

$$
J_{\mathrm{FG}}=2 \int_{\mathrm{F}}^{\mathrm{G}}\left((9 / 2) \bar{B} \sigma_{x y}^{4}-\rho g \sin \alpha u\right) \mathrm{d} y .
$$

However, the stress at FG will be an order of magnitude less than the stress $\sigma_{x x}$ at $\mathrm{HK}$ and this applies to the velocity $u$ as well (McMeeking and Johnson, 1985). Thus the contribution to $J$ from FG can be neglected in favour of that from HK.

Finally, we consider the contribution from кв. Here, $\mathrm{d} y=0$ and $v=0$, so $n \cdot \sigma \cdot(\partial u / \partial x)=-_{x y}(\partial u / \partial x)$. We note that in our model at the base in the sliding region $\sigma_{x y}=\tau_{s}$ which is uniform. Consequently,

$$
J_{\mathrm{KB}}=2 \int_{\mathrm{KB}} \tau_{\mathrm{s}}(\partial u / \partial x) \mathrm{d} x=2 \tau_{\mathrm{s}}\left(u\left(x_{\mathrm{B}}\right)-u\left(x_{\mathrm{K}}\right)\right)=-2 \tau_{\mathrm{s}} u\left(x_{\mathrm{K}}\right) .
$$

Taking all the leading-order contributions, we find

$$
J_{\mathbf{B}}=(3 / 16) \bar{B}\left(\sigma_{x x}\left(x_{\mathrm{K}}\right)\right)^{4} h+2\left(\rho g h \sin \alpha-\tau_{\mathrm{S}}\right) u\left(x_{\mathrm{K}}\right) .
$$

We can demonstrate that $J$ is independent of the position $x_{K}$ by differentiating to find

$$
\begin{aligned}
\partial J / \partial x_{\mathbf{K}} & =(3 / 4) \bar{B}\left(\sigma_{x x}\left(x_{\mathbf{K}}\right)\right)^{3} h\left(\mathrm{~d} \sigma_{x x} / \mathrm{d} x\right)_{x}=x_{\mathbf{K}}+ \\
& +2\left(\rho g h \sin \alpha-\tau_{\mathrm{S}}\right)(\mathrm{d} u / \mathrm{d} x)_{x}=x_{\mathbf{K}} .
\end{aligned}
$$

We substitute using Equation (11) to show that

$$
\begin{aligned}
\partial J / \partial x_{\mathrm{K}} & =2(\mathrm{~d} u / \mathrm{d} x)_{x}=x_{\mathrm{K}}\left[h\left(\mathrm{~d} \sigma_{x x} / \mathrm{d} x\right)_{x}=x_{\mathrm{K}}+\right. \\
& \left.+\rho g h \sin \alpha-\tau_{\mathrm{s}}\right]
\end{aligned}
$$

which is zero by Equation (8). Thus $\mathbf{K}$ can be chosen to lie anywhere up to the discontinuity and that is the most convenient position. Since $u\left(x_{\mathrm{B}}\right)=0$, this gives the result for $J$ at B

$$
J_{\mathrm{B}}=(3 / 16) \bar{B}\left(\sigma_{x x}\left(x_{\mathrm{B}}\right)\right)^{4} h .
$$

